\title{
Inhabiting SCOPUS: Navigating Modern Controversies with Performative Approaches in a Public Speaking Course
}

\section{Lane Sorensen}

\begin{abstract}
COLL-P155 is an undergraduate public speaking course in which students give speeches on modern public controversies such as capital punishment, abortion, immigration, etc; in other words, issues for which many might hold a definite - at times inflexible - bias. In order to mitigate such biases, the concept of scopus, moving out of one perspective to inhabit another (Arthos, 2017a: Lecture 11), is situated in the goals of the speech assignments and combined with the theoretical and practical benefits of drama pedagogy as illustrated by Even (2008). Following a description of the speech assignments is a pedagogical reflection of activities that combine scopus and drama pedagogy to get students up and out of their seats in order to act out frames of mind that might embody perspectives drastically different from their own. From encouraging ad-hominem attacks in fictitious arguments about favorite foods to highlight the counterproductive and harmful nature of alienating language, to acting out a Grimm's fairytale from the villain's perspective to encourage empathy with an unpopular position, the lessons of openmindedness and civility emphasized in these performative activities can be transferred to discourse surrounding real-world controversies.
\end{abstract}

\section{Introduction}

COLL-P155, or Public Oral Communication (henceforth 'P.O.C.'), at Indiana University-Bloomington is a foundational course required of all undergraduate students in the College of Arts and Sciences, instructing approximately twelve hundred students per semester, with a maximum of twenty-four per section. The course is worth three credit units and has two primary components: the lab section, which meets twice a week for fifty minutes during the day (multiple, parallel sections are scheduled from $8 \mathrm{am}$ to $3 \mathrm{pm}$ ) for one semester, approximately fifteen weeks. Each section is led by one of over thirty associate instructors from various departments within the College of Arts and Sciences (hence my background as an instructor of German as a 
foreign language in the Department of Germanic Studies), and is the forum in which students prepare and give speeches in front of their peers. Associate instructors are responsible for preparing lab activities, taking attendance, and grading student participation, outlines, and speeches. The second component is a fifty-minute lecture providing the theoretical foundation of rhetoric as a discipline and the objectives of specific speech assignments, prepared and given each week by the course director, John Arthos, Ph.D. Due to limited time and space, this lecture is recorded every Wednesday during the semester with a live audience of approximately twenty students from one arranged section, and uploaded shortly thereafter to Canvas, Indiana University's online interface, where access to content is restricted to users of each course section, i.e. instructors and registered students. Additionally, each lecture features a picture-in-picture mode that allows students to simultaneously watch the lecturer engage with the class and view PowerPoint slides that introduce and summarize key theoretical points. Although this is a beginning-level course, it is not uncommon to have an equal proportion of first through fourth-year students in the classroom, and their curriculum backgrounds and majors vary greatly, as well, from psychology, nutrition, and foreign languages to media and communication studies, anthropology, and chemistry. International students from all corners of the world who possess at least an intermediate command of English further add to this diversity, bringing with them perspectives that broaden our understanding of the world far beyond small town Indiana and the United States. In this course, students learn how to construct and deliver a complex argument extemporaneously with the audience and occasion in mind, develop techniques for reducing speech anxiety, and employ logos (logic), ethos (character), and pathos (emotion) to speak eloquently without resorting to the manipulation and deceit of sophistry (Arthos \& Smith, 2017). Most importantly, in order to cultivate community and humanity, the goal of P.O.C. is for students to

discover the power of speech to motivate, clarify, inspire, correct misunderstanding, advance a cause, exercise tact, speak truth to power, expose fallacies and presumptions, and work through problems collectively. (ibid.)

If we as educators subscribe to the notion that open-mindedness is good and that overgeneralizations are bad, then it is crucial that we understand the difference between merely voicing these ideals and actually living them. Chances are the reader has at least once in her life found herself in a situation in which she was shut down or endured ad-hominem attacks for voicing a controversial opinion. And as frustrating as it is to be on the receiving end of such encounters, it is just as likely that each and every one of us has had a hand in the quick judgement or public shaming of someone else at least once in our lifetime, as well. P.O.C. is therefore also about repairing and sustaining a sense of community in the aftermath of such bitter encounters by teaching students how to think critically and approach discussion of polarizing subjects with open ears, patience, and 
intense scrutiny of the evidence and logic of argumentation. This is not a course for students who wish to debate who the better professional athlete or musician is, nor is it a course about using sophistry to trick others into agreeing with your own point of view. It is a course about building community between people of different backgrounds and beliefs, about building understanding rather than collecting quick wins, about learning to live and at times disagree with others without resorting to petty actions or violence. Or, in the words of Arthos (2017d: Lecture 1), "P.O.C is the power of speech to achieve the common good with and for others in just institutions," one which lives in harmony with the five pillars of a liberal arts education: "question critically, think logically, communicate clearly, act creatively, live ethically."1 As lofty as these ideals sound, they are not unreachable, and it is our duty as educators to remind our students of the power they have to shape the world around them. If they are to rise to action demanded of them by a rhetorical situation, as Bitzer (1968: 1, 3) argues, they must understand that "there are circumstances of this or that kind of structure which are recognized as ethical, dangerous, or embarrassing (...). [But] every audience at any moment is capable of being changed in some way by speech." Key to this power and working to "achieve the common good" is the concept of scopus (Latin for 'target,' from Ancient Greek $\sigma x о \pi$ ó $)$ ), which encourages us to glimpse the world beyond our own biased perspectives in order to view an issue with a different set of eyes. Essentially, "scopus is coming from a position and arriving at a new place," which we can do because we have the power to listen and speak to inform and change our frame of mind (Arthos 2017c: Lecture 3). The following is an account of the visual aid used in Lecture 3 to explain this theory further: a box hidden under a cloth is placed onto a table, situated between two students at opposite ends. When the cloth is removed, both students are asked to describe the color of the box. Disagreement ensues, as one student claims that the box is red, whereas the other is certain it is green. Through the screen, however, we the viewers of the lecture online see the box from a different angle: the box is indeed green, but only on two sides; the other two sides are red. It is our perspective from the side that is able to inform the two students sitting at opposite ends of the box that they are both right. The conclusion drawn from this is that, just as a tangible object can be perceived differently depending on the perspective of the observer, public issues are perceived differently from different vantage points, as well. In other words,

[...] scopus is not saying that only one view of a situation is right. It's saying that human beings are complicated, that situations are complicated, that each of us can look at an issue in more than one way, and within our own complexity we can look at something in a different way. (Arthos 2017a: Lecture 11)

As down to earth and seemingly obvious as the truth of this passage is, we only need look at the twenty-four-hour news cycle to see that the virtue of

\footnotetext{
${ }^{1}$ All lecture quotes by John Arthos, Ph.D. in this paper were delivered to instructors and students in print via PowerPoint slides available in the relevant lectures.
} 
understanding complexity is all too often traded for loud overgeneralizations, sensationalistic stories, and horrific acts of violence. Scopus is not a magical method to replace the woes of the world with perpetual harmony and easy solutions, it is a reminder that it takes work - sometimes excruciating work to cope with a perspective drastically different from one's own without losing civility. Therefore it is both acceptable and necessary to use our ability to listen and speak to each other in order to communicate these different perspectives and inhabit them by moving from one position to another. It is this emphasis on movement from one place to another to encourage sympathy and eventually empathy that makes drama pedagogy a suitable framework for putting scopus into practice. Since we instructors want students to get comfortable looking at an issue from different perspectives, we are asking them to inhabit different roles and the personae behind those roles, if even for only several minutes. In other words, we are asking them to step outside of themselves and participate in drama. Even (2008: 162f) describes the advantages to this approach:

\begin{abstract}
Drama pedagogy stands out from other teaching and learning approaches in that both kinesthetic and emotional dimensions are strongly brought into play (...). The fictional context of drama situations serves as a safety zone in which learners can enjoy the freedom of being someone else and the freedom to behave in non-routine ways. At the same time, the learners are beholden to the worlds they have co-constructed; they are committed to the characteristics of the personae and places they have collaboratively invented, and they have to take the consequences for their own actions within these worlds.
\end{abstract}

Although Even (ibid.) employs drama pedagogy to facilitate foreign language learning, this approach is also ideal for P.O.C., where learners are encouraged not only to move from their routine position to a new perspective (scopus), but also commit themselves to that new place by considering where they stand and how their new persona perceives the issue at hand (inhabitation). I call the practice of this theoretical movement and commitment 'inhabiting scopus'. Before we get to the performative activities rooted in this theory, I will describe the speaking assignments that call for them in the first place.

\title{
2 The Speech Assignments
}

This section describes the four speech assignments designed by Arthos and Smith (2017), presented here in the chronological sequence they take in the course. Whereas the first, public community speech is held already on the second day of class in order for peers to introduce each other, each of the three speech assignments that follow is preceded by two to three weeks of preparation involving online assignments related to the lectures, activities on how to find research materials and construct an outline, and practice speaking extemporaneously with the use of note cards. The performative activities described in section 3 are held during these preparatory intervals and pertain to the second, third, and fourth speech assignments. 


\subsection{Public Community Speech}

The primary function of the first speech of the course is designed to build community from the get-go and give students a chance to speak in front of the class without the stress of wondering how I will grade it. This is the public community speech in which they introduce a classmate at the front of the room, highlighting the uniqueness of their partner and how that adds to the diversity of the class community and the university as a whole. It takes one to two minutes, and regardless of how this actually goes, students know that by getting up and doing it, they will receive full points for this assignment; however, they still receive written feedback from me on what went well and what can be improved upon for the next speech. Although the instructions for this assignment are simple enough, its overarching message is resoundingly important:

A public is a group of people so large that no one could personally know everyone, but whose members are connected by their identity as citizens. This means that they belong for convenience and protection to a community larger than any of their particular interests, activities, or values. Because a public is by definition a group with different values, interests, passions and positions, a speech that unites a public through speaking and listening is an invitation to honor our having a public space in common. (Arthos, 2017d: Lecture 1)

\subsection{Sympathetic Perspectives Speech}

Scopus is already an integral part of the second speech, sympathetic perspectives, wherein students must not merely portray at least two opposing perspectives on a modern public controversy, but inhabit those positions with the full weight of their being within four to six minutes (the length of the last two speeches, as well), lest we see their own personal bias shining through. For this and the remaining speech assignments, students must conduct their own research, citing sources properly in parenthetical and bibliographic form in initial and final outline stages, as well as during their speeches. From their accounts and my own observations, I gather that this is the first time many of the students have conducted serious academic research on a perspective at odds with their own, which gets them closer to understanding the real diversity of a public.

\subsection{Invitational Speech}

After they have experienced their first round of timed and graded public speaking, we move on to the invitational speech assignment, for which students choose a position - preferably one that is relatively unpopular among that group of students or with which the speaker disagrees - and argue in favor of that perspective without alienating other perspectives in the process. Key to this is avoiding loaded language (e.g. "The heartless, antiquated views of X should be defeated with legislation Y" vs. "Although supporters of X are not in favor of 
$\mathrm{Y}$, the latter is an appropriate measure to address matter Z") and establishing common ground right from the start.

Inspired by feminist principles, Foss and Griffin (1995: 5) define invitational rhetoric as

an invitation to understanding as a means to create a relationship rooted in equality, immanent value, and self-determination. Invitational rhetoric constitutes an invitation to the audience to enter the rhetor's world and to see it as the rhetor does. In presenting a particular perspective, the invitational rhetor does not judge or denigrate others' perspectives but is open to and tries to appreciate and validate those perspectives, even if they differ dramatically from the rhetor's own.

From the excerpt above we can see that this is not the same as a persuasive speech. Indeed, its primary goal is not to persuade the audience, but to foster understanding. If the audience happens to be persuaded in the process, however, then it is not an unwelcome result.

\subsection{Transformational Speech}

The fourth and final speaking assignment is the transformational speech, the goal of which is to

find the straw that will break the camel's back of [a] belief system. You want to find the weakest link in that representation system and discredit it so that the whole house of cards collapses. (Arthos 2017b: Lecture 10)

This is by far the most theoretically complex and challenging speech for students to prepare, yet the payoff is extraordinary when done well. The speech opens with a personal account - whether connected to the speaker or an anecdote about a single individual or family - that illustrates a transformation in how that human being came to look at a particular issue in a way different from before. This is the conversion story. Followed by a claim that describes the problem at hand and how we can address it, students must then describe the ideonode ("any single piece of an ideological system"...e.g. symbol, doxa, practice; ibid.) at the root of the problem. Thereafter, they are to undermine it with evidence or swap it for another ideonode entirely in order to render the entire ideoplex (network of connected ideonodes, a.k.a. ideology; ibid.) unstable, and therefore worthy of public action to re-evaluate or even reconfigure that ideology. To make sure we are on the same page, I offer the following example that follows the structure required of a transformational speech in this course:

1. Conversion story: you begin by describing that you grew up in a household in which the words "welfare mom" stood for a person who receives benefits from taxpayer-funded governmental assistance programs without working or applying for work. You were told by your parents who heard it from the news and their own families - that such individuals in turn encourage laziness in their own children and are why welfare and 
any ideology supporting it are detrimental to our way of life. Years of this reinforcement have hardened your perspective against welfare and its recipients until you meet a widow who has no choice but to collect welfare benefits because she cannot feed her kids with the paltry income from her minimum-wage, part-time job, and she has no support from her own family. This does not fit the lazy, manipulative welfare mom narrative you have been fed by family and friends, so your speech claim challenges the validity of this narrative.

2. Ideonode: you then go on to describe the origins and pervasiveness of this lazy welfare mom ideonode before offering data from multiple, credible sources that sound a lot like the widow you talked about before. Although this transformation in your perspective might constitute a very black and white picture of the issue (i.e. lazy vs. unfortunate, but nothing in between), the shift in perspective from one extreme to another has made you question whether more examples exist that also do not fit the negative, lazy stereotype. You soon discover more data suggesting that most welfare recipients are neither lazy nor widowed, but encounter a combination of major, temporary setbacks and low external support.

3. Exchange: after presenting information illustrating that the lazy welfare mom stereotype (ideonode) is deeply flawed, you remind your audience that we can affect change with the power of speech, so you propose exchanging the ideonode for a more nuanced and compassionate understanding of welfare recipients in order to challenge and actively dispel not only the harmful and inaccurate lazy welfare mom/recipient stereotype, but other potentially unfounded negative associations with welfare, as well. This call to action may even include encouraging your audience to support local, current legislation in favor of retaining or expanding welfare assistance. It is this call to action that links a change of heart about an issue to a solution-driven approach. Returning to the widow from your conversion story, you describe how she, thanks to welfare assistance, is in a better financial place, with plans even to return to university to complete her degree and become a social worker. With skillful emotion and eloquence, the speaker brings us, the audience, to see the widow as a multi-faceted human being with aspirations, one of many for whom welfare assistance was designed. Whereas pity might acknowledge, but do nothing about a problem, the aim of the transformational speech is to highlight the distorting nature of an ideonode and inspire us to solve the problem with the power of communication. Many students have told me how difficult, yet how rewarding this assignment is, and that they found great value in learning that "you will get someone to budge only if you first understand why they have such a fixed commitment" (ibid.).

Beyond the gesturing and movement that are an integral, graded part of style and delivery for the aforementioned speaking assignments, it is evident that 
included therein is a great amount of theoretical movement, as well. The work it takes to get to the heart of a perspective and understand its reaction to other perspectives is the movement entailed in scopus and inhabiting that position as if it were one's own. I propose that both kinds of movement - physical and theoretical - can be paired and practiced in activities grounded in performativity that not only enhance students' ability to navigate the assignment goals, but also galvanize their interest in the material while fostering a sense of community among participants.

\section{Preparation with Performative Activities ${ }^{2}$}

The performative activities described in this section were carried out in the classroom fitting about twenty-four students where we did not have the amenities of a full theatrical stage, costumes, or props. Nevertheless, students rose to the occasion and enlivened that dreary, windowless space with great energy, enthusiasm, and creativity. Both directly after these activities and in their end-of-the-semester evaluations, many students reported that these were their favorite class moments, tying fun with the function of preparing them for major speaking assignments. Furthermore, students who seemed at first quite shy surprised me by breaking out of their safe shells to act with great zeal and hilarity, bringing them closer to their peers and encouraging those around them to participate in like fashion. The laughter and joy these activities brought to the class made for such a welcoming and spirited environment that endured throughout the semester, likely contributing to the civility I witnessed when it came time to discuss heavier matters such as domestic violence and immigration policy.

\subsection{Favorite Food Alienation Game}

One of my first - and favorite - performative activities in the course is one that easily precedes or follows the public community speech and requires little preparation, but introduces an important concept relevant to the final three speech assignments. A spin on the simple question, was ist dein Lieblingsessen? of my German-teaching days, which entailed students getting up and moving around the room to practice asking and listening to a variety of responses

\footnotetext{
${ }^{2}$ For the sake of space, I have omitted several smaller performative activities that are not as grounded in scopus, e.g. walking around in silence and communicating with gestures only or charades with delivery do's and do not's, where students perform an impromptu review of a movie or restaurant before a group while incorporating two randomly selected public speaking faux-pas, such as speaking monotonously or not engaging in eye contact with the audience. I would like also to thank Kelly Casper-Kushman and Laura Roush for informing me of the latter activity, Bridget Elchert, Dan Johnston, and David Watters for their mock town hall meeting, as well as Whit Emerson, Laura Roush, and Bridget Sutherland for their villain's perspective spin on the classic fairytale. These and other talented P.O.C. instructors under the guidance and enthusiasm of course director, John Arthos, Ph.D, and course coordinator, Cynthia Smith, Ph.D, made this course the success it was and continues to be.
} 
from multiple classmates, I thought the same question - this time in English could emphasize the variety of diverse tastes inherent in a public. This time, however, I introduced alienating language into the mix: if two students had the same favorite food, they should lavish each other with compliments or other signs of approbation (e.g. thumbs-up, hugs, high-fives, etc.). But if they had different favorite foods, they were to hurl ad-hominem attacks at the other, interrupt with sarcastic remarks, and/or leave abruptly showing clear signs of displeasure. ${ }^{3}$ Not only did students get to move around (a bit of exercise goes a long way at 8am in a windowless room) and learn more about their classmates, but they also relished the opportunity to be a little mean to each other, perhaps benefiting from the cathartic release of anger and frustration induced by the stresses of dorm life, their studies, and having to show up to a required public speaking course at $8 \mathrm{am}$ in a windowless room. More than just an interesting and at times hilarious way for students to interact with one another, there is a deeper motive to this exercise: your favorite food might be one that is accompanied by fond memories or positive associations rooted in childhood experiences, the connections to which are far more emotional than logical. This emotional connection cannot simply be cast aside in favor of pure reason at all times if, as Arthos (ibid.) argues, we should first understand why someone has such strong convictions. Kastely (2004: 223) further emphasizes the role of emotion in rhetoric, stating that

First, our deepest convictions are not simply or primarily products of logical thought. Rather, they arise out of our having lived particular lives and are inescapably tied to those lives. Second, these principles do not feel as if they were deliberately adopted; instead, they feel as if they are givens for us. They are part of the fabric of our lives, and we feel their authority in our emotional responses. The fact that these values are not easily altered by a reasoned discourse suggests the depth at which the emotions operate and argues that they are rooted in sources anterior to reason.

Although disagreement over a person's favorite food is clearly not the same as heated political or religious debate, the above passage suggests that, just as subjective, emotional connections can influence one's favorite food, these kinds of connections are also inextricably linked to our opinions on more serious matters, such as politics and religion. The point of this exercise is to show that ad-hominem attacks and sarcastic remarks in response to a deeply held conviction or emotional connection - regardless of the matter at hand - lead to an intense, bitter encounter. Importantly, Klofstad et al (2013: 124) provide evidence that this is counterproductive, stating that "intense disagreement may inhibit learning as people seek to avoid personal relationships that put conflict front-and-center." By letting students emulate intense disagreements with lighter-hearted topics such as the superiority of one food over another, they

\footnotetext{
${ }^{3}$ Students were asked to refrain from using sexist, xenophobic, etc. slurs or physical acts of aggression, which violate university policy and can threaten public safety.
} 
get a taste of the absurdity of neglecting the other party's personal experiences, and are reminded that alienating language and behavior is counterproductive and should be avoided for all speaking assignments, including the question and answer period after each speech.

The aim, then, is to transport the lessons learned from this exercise to the realm of debating less light-hearted matters, modern public controversies such as the Israeli-Palestinian conflict, climate change denial, etc. Whereas the favorite food alienation game requires no prior research on the part of the students, they are required to conduct rigorous research on the speech topics they choose and cite sources in parenthetical and bibliographic format for source organizer, initial- and final outline assignments (which are graded and due in stages before sympathetic perspectives, invitational, and transformational speeches), as well as cite sources orally in every speech. This process is facilitated by a guide to opposing viewpoints in context, an online resource available to P.O.C. students that provides a range of material from peer-reviewed journals, statistical information, charts, graphs, public opinion polls, eyewitness accounts, audio and video interviews, etc. on thousands of topics worldwide, all of which include a thorough list of cited material to which students can turn. Proper citation and style guides are included in this resource, as well. Students are not limited to this resource, and we discuss levels of source credibility and the perils of citing personal websites and social media links at the beginning of the course and remind students throughout the preparatory source organizer and outline stages.

\subsection{Mock Town Hall Meeting}

An effective activity that embraces scopus is the mock town hall meeting, which is held before the sympathetic perspectives speech. Such meetings are an integral part of the American political campaign landscape, and examples of heated arguments between town residents and politicians, and between the residents themselves abound in the news during campaign season. This means that, even if students have never taken part in a town hall meeting, it is very likely that they know what one looks like from the news or have family or friends who have attended one. Therefore this activity requires little explanation before the class can jump right in. I offer the following layout of what this town hall meeting looks like for a class of under twenty-five students: the instructor asks students to brainstorm controversies - local, if possible that are currently hot in the community. After listing several on the board for all to see, the class is divided into groups of at least four or five, whereupon each group selects one of the issues listed on the board. It is then up to each group to decide the cast of characters, i.e. the different kinds of individuals who might have a stake in the issue at hand. Once this is decided, each person assumes the role of that character, creating their own socio-economic, ethnic, and/or religious background, personality, motivation for attending the meeting, etc. It is important that groups are given ample time to do this (e.g. twenty minutes) 
and engage in discussion throughout. What follows can be modified to cater to each instructor's expectations and time restrictions, but it is important that each group acts out or at least describes its set of characters in front of the class, even if no debate is featured. This has two key functions: 1 ) by creating a new persona, students have the opportunity to flex their creativity, reflect on the circumstances their characters might face in reality, and take the time to inhabit a character's perspective on a given issue; 2) by watching the diversity of characters unfold in other groups and one's own group, students are exposed to the diversity of a true public and therefore multiple and often opposing viewpoints on a controversy, potentially for the first time in their lives if it is an issue they are unfamiliar with or only ever have heard one side.

The beauty of this activity is that it directly prepares students for the sympathetic perspectives speech, allowing them to draw from the two or more opposing perspectives featured in theirs or another group if the matter discussed is a modern public controversy. Even if a group chooses a less grave issue, such as the addition of parking meters downtown, it is still one that affects the lives of individuals of various backgrounds and occupations in one way or another. From local business owners, single parents, and college students advocating for cheaper parking to encourage patronage and reasonable turnover, to municipal tax officials and tourist boards seeking to keep finances afloat and fund future projects, a veritable host of personalities and motives are at play from which one easily can deduce that virtually no issue is one-sided and communities must remain civil in the face of disagreement, because disagreement is often unavoidable. With this practice, students come to terms with the reality of diverse perspectives on all issues, including serious controversies that feature life-and-death consequences.

\subsection{Fairytale from the Villain's Perspective}

Most of us are familiar with the wickedness of granny-eating wolves and the ruthlessness of narcissistic queens from Grimm's and other fairy-tales, but how often have you pondered their perspectives? At the risk of being more devil than devil's advocate, this activity gives students creative license to re-write and perform their take on a fairytale in front of the class. The only stipulations are that the focus of the performance is on the villain's perspective, and that the villain must avoid alienating the audience or the other characters by avoiding loaded language and incendiary argumentation. This activity is held before the invitational speech, which requires students to avoid loaded language and encourages them to inhabit a potentially unpopular perspective, and is implemented again before the transformational speech. Of all of the performative activities I used in this course, this one has the greatest theatrical potential with regard to planned and improvised movement. Here, students are free to jump, crawl about, form still scenes, and even dance the robot if such is part of their new take on a fairytale.

To assign random groups, I often print colorful pictures associated with 
the theme of the day (in this case, illustrations of various fairytales) and cut them into four or so pieces, which students draw from an envelope, while the complete pictures are projected on the screen as a guide. Once the peers and their puzzle pieces come together, they receive a brief, printed synopsis of their fairytale so that everyone in the group is more or less on the same page, and now it is time to get to the work of re-writing the story from the villain's perspective. The stages of brainstorming, casting, blocking, notecard preparation, and acting work best when not rushed, so it is important to use the entire class period for this activity (fifty minutes in our case). What ensues is nothing short of wildly entertaining and vastly creative. The following are a couple of brief scenes that especially stuck with me: 1) to justify the intention of the witch to eat Hansel and Gretel, the student playing the witch staged a posthumous monologue in which she lamented the cursed irony of living in a house made of candy while struggling with type II diabetes. "It was nothing personal," she insists, "but a matter of survival: I had to stay away from candy. And I regret that Hansel and Gretel had no choice but to take me out before I could eat them." The two students playing Hansel and Gretel seem to sport a kind of malicious cheer at these remarks, all the while taking fake bites of a student playing the part of the witch's delicious abode. 2) After the stage is set by mouthing strange bubbling sounds, the narrator from our second example takes drags from his invisible cigarette while recounting the wolf's twisted discovery: "Little Red is not as innocent as she seems... she has been running meth cooked by grandma for years now, and we have the video evidence to prove it" (the drug exchange is acted out as if we were watching a cheesy crime scene re-enactment). We find out that the wolf was really an undercover agent whose intent was to arrest the suspects, not eat them! The fumes he breathed upon storming the lab, however, made him delirious, and he argues that he saw no other alternative than to dispose of granny when she lobbed vials of dangerous chemicals at him (likely in self-defense. The agent does appear to be a wolf, after all). In the end, though, Little Red got to the wolf before he could call for backup and she has been hailed ever since as the hero of the story, although in reality she framed him as the villain in a system that historically has only ever viewed wolves as dangerous villains.

This activity can be used in preparation for both invitational and transformational speeches in that it challenges students to argue in favor of a potentially unpopular perspective while avoiding alienating language as much as possible (e.g. "It was a matter of survival... I regret that Hansel and Gretel had no choice..."), and gives students the opportunity to employ a transformational moment to address and undermine a pervasive ideonode (e.g. the surprising discovery made by a dutiful civil servant - who happens to be a wolf - of Little Red and grandma's drug operation is at odds with the common narrative that wolves are inherently evil). Even if there is limited time and resources, turning your classroom into a theater is possible and worth it if students are given an unexpected challenge for which they can mobilize their creativity. By inhabiting the role of the apparent villain and offering evidence that runs counter to the 
audience's expectations or deeply held convictions, students gain experience inhabiting an entirely different perspective, in turn preparing them to tap into the logic and emotion of opposing sides to a modern public controversy. When the activity is over, the following leap from fairytale villain to opposing perspective is made clear: just as we encounter villains in fairytales, those who are social or political representatives of perspectives we disagree with on issues such as flag burning, capital punishment, abortion, gun control, immigration, drug legalization, etc. are vilified often in media and elsewhere, shaping narratives that overgeneralize experience and exacerbate personal biases. It is our collective responsibility, then, to minimize those potential distortions when conducting research on a perspective that we ourselves might disfavor. This is designed to encourage open-mindedness in the safety zone of fictitious situations and extend that open-mindedness to the classroom community so that students are less afraid to speak their mind on real, controversial issues and face disagreement with cited evidence and civility.

\section{Conclusion}

A course as common to university curricula and as important for society as P.O.C. calls for more than just theoretical foundation and outlining procedures if we expect students to engage with controversial themes in a manner that is both civil in discourse and based on understanding multiple perspectives. By employing activities rooted in scopus and providing a drama pedagogical platform for our fellow human beings to creatively - if not always comfortably - inhabit an alternative way of looking at an issue, we come closer to having a true public, a real community, unfold before us. If it is conventional to think that we speak in rooms and act on stage, I invite the reader to reconsider the potential good of theater and performative opportunities if we are more ready to incorporate them into our everyday lives, because in the words of the philosopher William James (1896: 30),

In either case we act, taking our life in our hands. No one of us ought to issue vetoes to the other, nor should we bandy words of abuse. We ought, on the contrary, delicately and profoundly to respect one another's mental freedom: then only shall we bring about the intellectual republic; then only shall we have that spirit of inner tolerance without which all our outer tolerance is soulless, and which is empiricism's glory; then only shall we live and let live, in speculative as well as in practical things.

Even if key lessons learned spring out of lighter-hearted scenarios or improbable realities, the physical and theoretical movement it takes to engage with those scenarios is just as applicable and significant to the world beyond the classroom walls. This, I argue, is the seriousness of fiction, and why a performative approach to navigating modern public controversies is worth our time and effort. 


\section{Bibliography}

Arthos, John \& Smith, Cynthia (2017): COLL-P155 Public Oral Communication Course

Syllabus. College of Arts and Sciences, Indiana University-Bloomington. Microsoft

Word file

Arthos, John (2017a): Lecture 11: Three Transformation Speeches. Public Oral Communication. Indiana University-Bloomington. April 12, 2017. Lecture

Arthos, John (2017b): Lecture 10: Speech of Transformation. Public Oral Communication.

Indiana University-Bloomington. March 29, 2017. Lecture

Arthos, John (2017c): Lecture 3: Audience. Public Oral Communication. Indiana University-

Bloomington. January 25, 2017. Lecture

Arthos, John (2017d): Lecture 1: Course Introduction. Public Oral Communication. Indiana

University-Bloomington. January 11, 2017. Lecture

Bitzer, Lloyd (1968): The Rhetorical Situation. In: Philosophy and Rhetoric, Supplementary

Issue, 1992. University Park: Pennsylvania State University, 1-14

Even, Susanne (2008): Moving in(to) Imaginary Worlds: Drama Pedagogy for Foreign Language Teaching and Learning. In: Unterrichtspraxis Deutsch $41 / 2,161-170$

Foss, Sonja K. \& Griffin, Cindy L. (1995): Beyond Persuasion: A Proposal for an Invitational Rhetoric. In: Communication Monographs 62/1, 2-18

James, William (1896): The Will to Believe. In: James, William: The Will to Believe and Other Essays in Popular Philosophy. New York: Dover Publications, Inc., 1-31

Kastely, James (2004): Pathos: Rhetoric and Emotion. In: Jost, Walter \& Olmsted, Wendy (eds.): A Companion to Rhetoric and Rhetorical Criticism. Malden, MA: Blackwell, 221-237

Klofstad, Casey A.; Sokhey, Anand Edward \& McClurg, Scott D. (2013): Disagreeing about Disagreement: How Conflict in Social Networks Affects Political Behavior. In: American Journal of Political Science 57/1, 120-134 